\title{
GREATER FEMALE COMMUNALITIES IN PRENATAL HAND AND DENTAL DEVELOPMENT
}

\author{
A. R. Burdi, S. M. GARN and W. J. BABler \\ Department of Anatomy and Center for Human Growth and Development, The University of \\ Michigan, Ann Arbor, Michigan 48104, U.S.A.
}

\begin{abstract}
Summary-As shown in 15 male and 17 female developmentally-normal, 6-9 week (15-47 mm crown-rump length) embryos, intercorrelations (communalities) involving both mesial and distal deciduous teeth and proximal and distal segments of the developing hand were systematically higher in female embryos than in male embryos, without exception, a finding in surprising accordance with postnatal dimensional and temporal development of the dentition and of the appendicular skeleton.
\end{abstract}

\section{INTRODUCTION}

In human postnatal development, developmental communalities (as shown by correlations) are systematically higher for girls than they are for boys. This is true for most linear dimensions, such as tubular bone lengths, and for such discrete temporal events such as the age at ossification of the nuclei of the epiphyses and the round bones (Garn and Rohmann, 1959, 1966). The tendency for within-girl (intra-girl) correlations to exceed comparable intra-boy correlations holds also for the permanent teeth, both for conventional mesiodistal crown diameters (Garn et al., 1965b), and for the calcification, root development and movement of the permanent teeth (Garn, Lewis and Kerewsky, 1965a; Garn, Rohmann and Silverman, 1967).

There is growing evidence, moreover, that the principle of greater developmental communality for girls compared with boys holds also for early prenatal dental development. This is true when comparing the embryological staging of isomeres and opponents, and when comparing communalities across the developing deciduous dentition (Garn, Burdi and Nagy, 1971; Garn and Burdi, 1971). Even when tooth stage is related to crown-rump length (CRL), female embryos show uniformly higher correlations than male embryos (Garn, Burdi and Miller, 1970).

In the present study, therefore, we have concerned ourselves with comparative developmental communalities of $15-47 \mathrm{~mm}$ human embryos (approx 6-9 week fertilization age) both within and between anatomical regions. Taking the developing hand and the developing dentition together into consideration, the question is whether-and to what extent-female embryos still show greater developmental communality or uniformity. We have explored this question within segments of the dentition (both mesial and distal) and segments of the hand (both proximal and distal) in carefully selected embryos of both sexes, all "normal" by both gross appearances, histories and careful histological examination.

\section{MATERIALS AND METHODS}

This study is based upon extensive microscopic examination of stained histological sections of 32 embryos, (15 male and 17 female) in the $15-47 \mathrm{~mm}$ crown-rump length range. All were both grossly and histologically normal, from normal (uterine) implantations rather than ectopic (tubal and abdominal) pregnancies, and excluded spontaneous abortions.

Complete bilateral examination was made of the developing dentition, and each of 20 deciduous teeth was rated or "staged" according to the following expanded schedule, following that previously described (Garn and Burdi, 1971, pp. 1410):

1. Dental lamina stage, primary epithelial bud.

2. Early bud stage, proliferation and further ingrowth.

3. Late bud stage, lack of flat base.

4. Early cap stage, (flat base).

5. Intermediate cap stage, (enamel knot).

6. Cap stage, (initial invagination).

7. Late cap stage, (secondary invagination).

8. Primal cap stage, (enamel niche).

9. Bell stage (no enamel knot).

For comparison, the hand region (both proximal and distal) was similarly studied, bone by bone, following the work of Streeter (1949) in part, and described by us in extenso, (see Garn, Burdi and Babler, 1973 and Fig. 1 of this paper).

1. Mesenchymal bone anlage.

2. Chondroblast formation and appearance of the cartilaginous model.

3. Chondrocyte differentiation and perichondrium formation. 
4. Chondrocyte proliferation.

5. Maturation of cartilaginous model.

6. Chondrocyte hypertrophy.

7. Bone formation (bone collar or distal tufts).

Intra-regional developmental communalities were analysed by comparing the summed stages for the mesial teeth with those of the distal teeth, and the proximal hand (comprising the distal radius and ulna) with the distal hand (i.e. the metacarpals and phalanges). Inter-regional communalities were analysed by comparing mesial and distal tooth development separately with proximal and distal hand development.

In making the computations, only those embryos with at least early tooth or hand development, and incomplete in at least some hand or tooth aspects, were employed.

\section{FINDINGS}

As shown in Table 1, developmental intercorrelations were generally high in the $15-47 \mathrm{~mm}$ embryos of both sexes. Overall, the 30 developmental intercorrelations averaged $0 \cdot 91$, pooling all of the correlational data. Within anatomical regions, correlations were highest for the hand $(0.98$ for the proximal hand vs the distal hand), slightly lower for the hand as compared with the deciduous dentition $(0.95)$, and lower still comparing the more mesial to the more distal deciduous teeth $(0 \cdot 83)$.

Systematically, however, the 15 developmental intercorrelations for 17 female embryos exceeded the comparable developmental intercorrelations for all 15 male embryos of comparable crown-rump length. This was true within the hand (proximal vs distal hand), and within the deciduous dentition (mesial teeth vs distal teeth), as well as between anatomical regions (proximal hand vs mesial teeth, proximal hand vs distal teeth, etc.) without a single exception.

By the simple sign test, $15: 0$ as against the chance or expected $7 \cdot 5: 7 \cdot 5$ distribution, the systematic sex difference in prenatal developmental correlations was highly significant, $\chi^{2}$ (chi-squared) values were in excess of 11.3 and as high as 15.0 using various corrections for continuity. Furthermore, the mean sex-specific values of $r$, calculated from $Z$ transforms of $r$ also differed significantly, when calculated as the difference between matched pairs.

The conclusion is that in $15-47 \mathrm{~mm}$ embryos, corresponding to the 6-9 week conception ages, prenatal developmental correlations $(r)$ involving the hand and the deciduous teeth versus the hand are in all cases higher for the female.

\section{DISCUSSION}

The results of this developmental investigation come to us as a surprise. The $15-47 \mathrm{~mm}$ embryo is still young, developmentally, and at the smaller crown-rump lengths, tooth development and differentiation of the hand components has scarcely begun. Moreover, in the crown-rump range considered, and especially below $30 \mathrm{~mm}$, the male tends to be systematically advanced over the female. We have shown this for palatal closure (Burdi and Silvey, 1969a, 1969b), for the deciduous dentition (Garn and Burdi, 1971) and, more recently, for the developing hand (Garn et al., 1974). It would appear therefore, that the higher developmental commun-

Table 1. Sex differences in prenatal development communalities*

\begin{tabular}{|c|c|c|c|c|c|c|c|c|c|c|c|c|}
\hline & \multicolumn{4}{|c|}{ Maxilla } & \multicolumn{4}{|c|}{ Mandible } & \multicolumn{4}{|c|}{ Hand } \\
\hline & \multicolumn{2}{|c|}{ Anterior } & \multicolumn{2}{|c|}{ Posterior } & \multicolumn{2}{|c|}{ Anterior } & \multicolumn{2}{|c|}{ Posterior } & \multicolumn{2}{|c|}{ Carpus } & \multicolumn{2}{|c|}{ Digits } \\
\hline & $N$ & $r$ & $N$ & $r$ & $N$ & $r$ & $N$ & $r$ & $N$ & $r$ & $N$ & $r$ \\
\hline \multirow{8}{*}{$\begin{array}{l}\text { Anterior } \\
\text { maxilla } \\
\text { Posterior } \\
\text { maxilla } \\
\text { Anterior } \\
\text { mandible } \\
\text { Posterior } \\
\text { mandible } \\
\text { Carpus } \\
\text { (hand) } \\
\text { Digits } \\
\text { (hand) }\end{array}$} & \multicolumn{12}{|c|}{ Males } \\
\hline & & & 15 & 0.72 & 15 & 0.97 & 15 & 0.70 & 15 & 0.94 & 15 & 0.91 \\
\hline & 17 & 0.90 & & & 15 & 0.81 & 15 & 0.94 & 15 & 0.70 & 15 & 0.81 \\
\hline & 17 & 0.98 & 17 & 0.84 & & & 15 & 0.80 & 15 & 0.91 & 15 & 0.90 \\
\hline & 17 & 0.88 & 17 & 0.09 & 17 & 0.83 & & & 15 & 0.63 & 15 & 0.60 \\
\hline & & & & & & & & & & & & \\
\hline & 17 & 0.98 & 17 & 0.83 & 17 & 0.96 & 17 & 0.85 & & & 15 & 0.97 \\
\hline & 17 & 0.97 & $\begin{array}{l}17 \\
\mathrm{Fe}\end{array}$ & $\begin{array}{r}0.85 \\
\text { tales }\end{array}$ & 17 & 0.97 & 17 & 0.86 & 17 & 0.98 & & \\
\hline
\end{tabular}

*Developmental intercorrelations for male embryos shown on the right side of the diagonal, those for $15-47 \mathrm{~mm}$ female embryos on the left side of the diagonal. 
ality shown for both postnatal dental and postnatal skeletal development of the female has its origins very early in embryonic development, and at a time when the male rather than the female is advanced for size.

One possible explanation for the higher postnatal developmental communality of the female, including higher age-to-age correlations for size and dental development, may lie in the paired $X$ chromosomes of the female karyotype. To the extent that both size and developmental timing may be at least partially determined by genes in the X chromosome, this could give an informational advantage to the $\mathrm{XX}$, albeit with a possibly greater developmental range, consistent with a "dosage effect" (cf. Garn, Lewis and Kerewsky, 1965a). This chromosomal explanation is now further tenable for the hand and the dentition, in the $15-47 \mathrm{~mm}$ crown-rump range, notwithstanding consistent male advancement in both hand and teeth.

A possible alternative explanation lies in the natural preselection of the male and female embryos studied, including the possibility that the female embryos were more "normal", notwithstanding very careful exclusion of gross and microscopic abnormalities (including neural tube defects, and abnormalities of the hand area), and abnormalities of implantation (i.e. ectopic pregnancies) as well. It is of some interest to observe, therefore, that even the latter, abnormal implantations show much the same trends toward male advancement for size (Garn, Burdi and Babler, 1974) but even greater female developmental communality.

Whatever the explanation, and acknowledging the possibility of sampling effects in the limited sample of 15-47 mm embryos, the 6-9 week female does appear to be developmentally more consistent (a) in the dentition, (b) in the deciduous dentition as compared with the hand and (c) within the hand. It would appear, therefore, that use of the dentition as an independent measure of developmental status in the early embryonic period may be slightly more appropriate for female embryos, but approximately equal in utility as compared with the developing hand skeleton.
Acknowledgements-This investment was supported, in part, by Grant DE03443 from the National Institute of Dental Research and by the Beatrice Stanton Medical Research Fund, University of Michigan. We appreciate the assistance of Paul Schelble in photomicrography and Dixie L. Farquharson for assistance in manuscript completion. All specimens described are contained within the Bradley M. Patten Embryological Research Collection of The University of Michigan, and further data may be obtained from the authors.

\section{REFERENCES}

Burdi A. R. and Silvey R. G. 1969a. The relationship of sex-associated facial profile reversal and stages of human palatal closure. Teratology 2, 297-303.

Burdi A. R. and Silvey R. G. 1969b. Sexual differences in closure of human palatal shelves. Cleft Pal. J. 6, 1-7.

Garn S. M. and Burdi A. R. 1971. Prenatal ordering and postnatal sequence in dental development. J. dent. Res. 50, 1407-1414.

Garn S. M., Burdi A. R. and Babler W. J. 1974. Male advancement in prenatal hand development. Am. J. Phys. Anthrop. 40, (in press).

Garn S. M., Burdi A. R., Miller R. L. and Nagy J. M. 1970. Prenatal dental development as a reference standard for embryonic status. J. dent. Res. 49, 894.

Garn S. M., Burdi A. R. and Nagy J. M. 1971. Distance gradient in prenatal dental development. J. dent. Res. 50, 785 .

Garn S. M., Lewis A. B. and Kerewsky R. S. 1965a. Genetic, nutritional, and maturational correlates of dental development. J. dent. Res. 44, 228-242.

Garn S. M., Lewis A. B., Kerewsky R. S. and Jegart K. 1965b. Sex differences in intraindividual tooth-size communalities. J. dent. Res. 44, 476-479.

Garn S. M. and Rohmann C. G. 1959. Communalities of the ossification centers of the hand and wrist. Am. J. Phys. Anthrop. 17, 319-323.

Garn S. M. and Rohmann C. G. 1966. "Communalities"' in ossification timing of the growing foot. Am. J. Phys. Anthrop. 24, 45-50.

Garn S. M., Rohmann C. G. and Silverman F. N. 1967. Radiographic standards for postnatal ossification and tooth calcification. Med. Radiog. 43, 45-66.

Streeter G. L. 1949. Developmental horizons in human embryos, a review of the histogenesis of cartilage and bone. Carnegie Inst. Wash. Pub. 583, Contrib. to Embryol. 33, 149-167.

\begin{abstract}
Résumé- Chez 15 embryons, de sexe masculin, et 17 embryons de sexe féminin, normalement développés, de 6-9 semaines (longueur vertex-coccyx 15-47 mm), les intercorrélations comportant les dents temporaires mésiales et distales et les segments proximaux et distaux de la main en voie de développement sont systématiquement plus élevées chez les embryons de sexe féminin, sans exception. Ce résultat est en accord avec le développement post-natal dimensionnel et temporel de la dentition et du squelette des extrémités.
\end{abstract}


Zusammenfassung-Wie an 15 männlichen und 17 weiblichen normalentwickelten. 6-9 Wochen alten Embryos (15-47 mm Scheitel-Steiß-Länge) dargestellt wird, waren die Interkorrelationen zwischen den mesialen und distalen Milchzälnnen sowie den proximalen und distalen Segmenten der sich entwickelnden Hand systematisch und ohne Ausnahme bei weiblichen Embryonen größer als bei männlichen; dieser Befund stimmt in überraschender Weise mit der postnatalen Längen- und Zeitentwicklung der Dentition und des Extremitätenskelettes überein. 
Plate 4 overleaf 


\section{Plate 1}

Fig. 1. Seven developmental stages of the skeletal components of the hand region as exemplified by the third metacarpal throughout. (1) The mesenchymal analage, the arrow pointing to condensation of chondrogenic cells within the musculo-skeletal mesenchymal mass. (2) Chondroblast formation showing differentiation of chondrogenic cells and (arrows) initial deposition of intcrcellular matrix. (3) Chondrocyte differentiation and, as indicated by the arrows, formation of perichondrium. (4) Chondrocyte proliferation. better-defined perichondrium shown by arrow. (5) Chondral maturity with welldelineated perichondrium (arrows) and predominance of mature chondrocytes. (6) Chondrocyte hypertrophy in the central region, indicated by arrow. (7) Subperiosteal bone collar formation, indicated by arrow. For the hand and for the teeth, developmental "scores" were obtained by summing the stages attained by the individual components (see Garn, Burdi and Babler, 1974, Fig. 1). 
Communalities in prenatal development

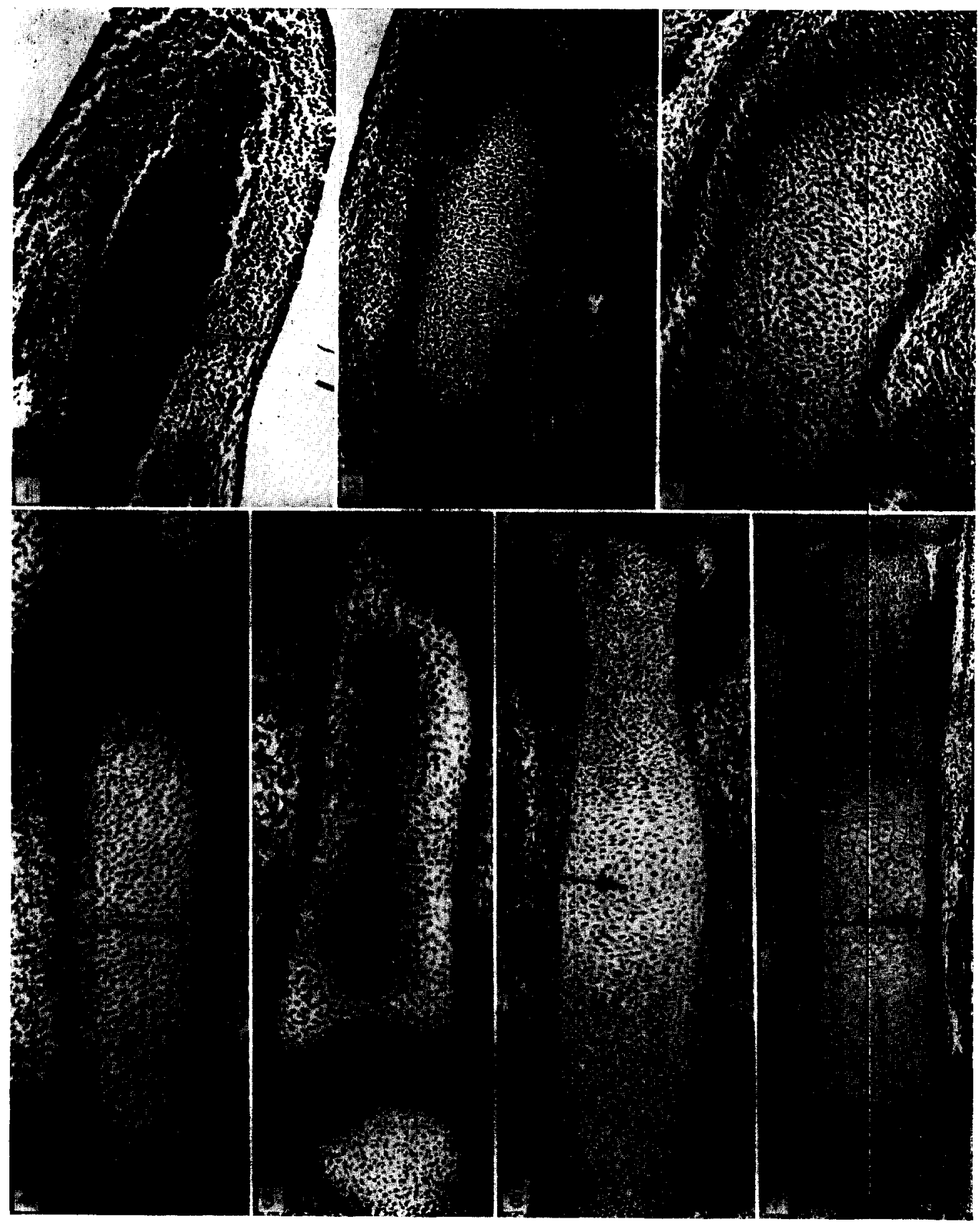

Plate 1

A.O.B. f.p. 466 